\title{
RESISTÊNCIA DO SOLO À PENETRAÇÃO EM PASTO DE CAPIM-TIFTON 85 SOB IRRIGAÇÃO E ADUBAÇÃO NITROGENADA
}

\footnotetext{
Marina Luciana Abreu de Melo ${ }^{1}$, Gabriela Soares Santos Araújo ${ }^{2}$, Eduardo Vieira Guimarães $^{3}$, Bruno Montoani Silva ${ }^{4}$, Samuel Petraccone Caixeta ${ }^{5}$

${ }^{1}$ Graduanda de Engenharia Agronômica da Universidade Federal de São João del-Rei / Bolsista CNPq (marinaluciana94@gmail.com) Minas Gerais - Brasil

${ }^{2}$ Graduanda de Engenharia Agronômica da Universidade Federal de São João del-

Rei / Bolsista FAPEMIG

${ }^{3}$ Graduando de Bacharelado Interdisciplinar em Biossistemas da Universidade

Federal de São João del-Rei/ Bolsista PIBEX UFSJ

${ }^{4}$ Professor Doutor do Departamento de Ciência do Solo da Universidade Federal de

Lavras

${ }^{5}$ Professor Doutor do Departamento de Ciências Agrárias da Universidade Federal de São João del-Rei
}

\section{Recebido em: 08/04/2017 - Aprovado em: 10/06/2017 - Publicado em: 20/06/2017 DOI: 10.18677/EnciBio 2017A93}

\section{RESUMO}

O uso de adubação orgânica, aliado à irrigação de pastagens com gramíneas vigorosas, podem proporcionar condições favoráveis ao desenvolvimento das plantas, refletindo na melhoria da qualidade estrutural do solo. $\mathrm{O}$ objetivo deste trabalho foi avaliar a resistência à penetração de um Latossolo Vermelho distrófico argiloso, cultivado com capim-tifton 85 e adubado com diferentes fontes nitrogenadas, sob sistema irrigado e de sequeiro, com a finalidade de averiguar se há manutenção da qualidade física do solo. Os tratamentos corresponderam a diferentes formas de suprimento de N: $400 \mathrm{~kg} / \mathrm{ha}$ de N, na forma de ureia (T1); 400 $\mathrm{kg} / \mathrm{ha}$ de N, na forma orgânica via esterco bovino (T2); $400 \mathrm{~kg} / \mathrm{ha}$ de N, 50\% na forma mineral e $50 \%$ na forma orgânica, utilizando-se as mesmas fontes (T3) e a testemunha, sem adubação nitrogenada (T4). Avaliou-se a resistência do solo à penetração (RP) até $50 \mathrm{~cm}$ de profundidade. A umidade do solo foi determinada nas camadas $0-20,20-40$ e 40-50 cm. Foram feitas análises de correlação de Pearson entre teor de matéria orgânica no solo (MOS) e RP nas camadas 0-5 e 5-10 cm. Não houve diferença significativa entre formas de adubação nitrogenada $(p<0,05)$, observando-se ausência de correlação significativa entre RP e MOS. No entanto, o uso da irrigação favoreceu a compactação do solo. A fonte de $\mathrm{N}$ para adubação de capim-tifton 85 indica ser pouco relevante para induzir modificações na RP, porém o regime hídrico foi um fator significativo, mesmo com a capacidade de descompactação biológica do solo atribuída à espécie utilizada.

PALAVRAS-CHAVE: compactação do solo, Cynodon sp., regime hídrico. 


\title{
SOIL PENETRATION RESISTANCE IN PASTURE OF CAPIM-TIFTON 85 UNDER IRRIGATION AND NITROGEN FERTILIZATION
}

\begin{abstract}
The organic fertilizers use, associated with irrigation of pastures with vigorous grasses, can provide favorable conditions for the plants development, reflecting on the the soil structural quality improvement. The aim of this work was to evaluate the penetration resistence of a clayey dystrophic Latosol, cultivated with Tifton 85 and fertilized with different nitrogen sources, under irrigated and rainfed systems, in order to determine if there is maintenance of soil physical quality. The treatments corresponded to different forms of $\mathrm{N}$ supply: $400 \mathrm{~kg} / \mathrm{ha}$ of $\mathrm{N}$, in the form of urea (T1); $400 \mathrm{~kg} / \mathrm{ha}$ of $\mathrm{N}$, in organic form via bovine manure (T2); $400 \mathrm{~kg} / \mathrm{ha}$ of $\mathrm{N}, 50 \%$ in mineral form and $50 \%$ in organic form, using the same sources (T3) and the control, without nitrogen fertilization (T4). The soil penetration resistence (PR) was evaluated up to $50 \mathrm{~cm}$ depth. Soil moisture was determined in the $0-20,20-40$ and $40-50 \mathrm{~cm}$ layers. Pearson correlation analyzes were performed between soil organic matter content (SOM) and PR at layers $0-5$ and $5-10 \mathrm{~cm}$. There was no significant difference between the treatments $(p<0.05)$, and there was no significant correlation between $\mathrm{PR}$ and SOM. However, the use of irrigation favored soil compaction. The $\mathrm{N}$ source for fertilization of Tifton 85 indicates to be little relevant to induce modifications in PR, but the water regime was a significant factor, even with the soil biological decompaction capacity of the used specie.
\end{abstract}

KEYWORDS: soil compaction, Cynodon sp., water regime.

\section{INTRODUÇÃO}

Os sistemas de criação de gado de leite no Brasil são fundamentados, basicamente, no uso de pastagens, sendo a sua degradação um dos principais problemas enfrentados pelos pecuaristas. Essa adversidade pode estar associada à escolha incorreta da forrageira, à adubação ineficiente, ao emprego de uma taxa indevida de lotação animal e ao manejo inadequado do solo (PERON \& EVANGELISTA, 2004, FIDALSKI et al., 2008). Esses aspectos são capazes de afetar a qualidade física (FIDALSKI et al., 2008), apresentando como uma das principais consequências a compactação do solo (OLIVEIRA et al., 2014). No caso de áreas de pastagem, a compactação ainda pode ser relacionada com a pressão exercida pela carga dos animais sobre o solo.

A compactação representa um dos maiores entraves da produção agropecuária em diversas regiões, uma vez que altera o comportamento da infiltração e escoamento da água no solo (OLIVEIRA et al., 2014). Além disso, o aumento do grau de compactação do solo resulta em acréscimo da sua resistência à penetração de raízes (NEIVA JúNIOR et al., 2015).

A resistência à penetração (RP) é um parâmetro que expressa o grau de compactação e a facilidade na qual as raízes penetram no solo (LLANILLO et al., 2006), sendo esse fator dependente da variabilidade temporal da umidade no solo (SILVEIRA et al., 2010; COSTA et al., 2012; TORRES et al., 2012; TAVARES et al., 2014). A excessiva resistência do solo acarreta danos ao sistema radicular e ao desenvolvimento das plantas. Ademais, esses problemas podem estar associados com a reduzida difusão de oxigênio em solos compactados (COSTA et al., 2012).

IMHOFF et al. (2000), analisando a aplicação da curva de resistência no controle da qualidade física em um solo sob pastagem, concluíram que valores de RP superiores a 2,50 MPa são limitantes ao desenvolvimento de pastagens perenes. 
BASSO et al. (2014), estudando a variabilidade da produção do capim-tifton 85 em um Latossolo Vermelho eutrófico típico e sua correlação com os atributos físicos do solo, constataram que as produções de massa verde e massa seca da forrageira apresentaram variabilidades consideradas de moderada a alta, exibindo correlações negativas com a resistência do solo à penetração.

O nitrogênio é o nutriente de maior importância para o aumento da produtividade das pastagens. Dessa forma, a adubação nitrogenada pode ser adotada com a finalidade de minimizar os efeitos do pisoteio animal, uma vez que uma maior produção de matéria verde reduziria a pressão aplicada pelo peso dos animais na superfície do solo (CARASSAl et al., 2011). Essa prática pode promover, ainda, melhorias na qualidade física do solo, já que proporciona incremento do teor de matéria orgânica e favorece a descompactação do solo por meio do desenvolvimento das raízes (SILVA et al., 2013).

Dentre as espécies usadas como forrageiras, destaca-se o capim-tifton 85, uma espécie do gênero Cynodon, originada por meio do cruzamento entre o capimtifton 68 e a espécie Bermuda Grass, proveniente da África do Sul. Essa gramínea é caracterizada por um sistema radicular robusto e com rápida renovação, atuando na descompactação biológica do solo. Esses fatores permitem, ainda, o emprego da espécie como um instrumento para recuperação de solos fisicamente degradados (COLUSSI et al., 2014).

Considerando que a adubação orgânica pode favorecer o incremento de matéria orgânica do solo, e que o uso da irrigação pode propiciar melhores condições para o desenvolvimento das plantas, aliado ao vigor vegetativo inerente às gramíneas do gênero Cynodon, o objetivo deste trabalho foi avaliar a resistência à penetração de um Latossolo Vermelho distrófico argiloso cultivado com capimtifton 85 e adubado com diferentes fontes nitrogenadas, em dois regimes hídricos.

\section{MATERIAL E MÉTODOS}

O estudo foi realizado em uma área de pastagem de capim-tifton 85, pertencente à Fazenda Experimental de Santa Rita da Empresa de Pesquisa Agropecuária de Minas Gerais, regional Centro-Oeste (EPAMIG/CTCO), localizada no município de Prudente de Moraes - MG, que apresenta latitude 19 $28^{\prime} 29^{\prime \prime} \mathrm{S}$,

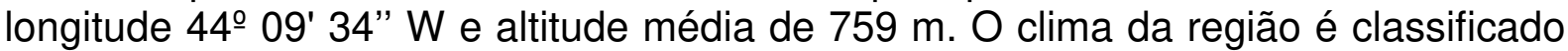
como subtropical úmido (Cwa), segundo Köppen-Geiger, apresentando temperatura média de $21,8^{\circ} \mathrm{C}$ e precipitação anual de $1.329 \mathrm{~mm}$ (IBGE, 2013). O solo do local foi classificado como Latossolo Vermelho distrófico (LVd) (EMBRAPA, 2013).

Em janeiro de 2011, foi realizada a implantação do experimento, por meio do preparo do solo com grade aradora e niveladora e posterior abertura de sulcos para o plantio da gramínea. A correção do solo foi feita por meio da aplicação de 02 toneladas de calcário dolomítico. Já a correção de plantio consistiu-se na aplicação a lanço de $578 \mathrm{Kg}$ de adubo 08:28:16 + Fritted Trace Element (FTE) e $650 \mathrm{Kg}$ de adubo 20:00:20. O plantio da forrageira foi realizado de forma manual, em março de 2011, sendo efetivada a renovação do pasto em outubro do mesmo ano.

A área experimental é constituída por aproximadamente 1,8 hectares, sendo subdividida em 24 piquetes de $18 \times 40 \mathrm{~m}$, destinados ao pastejo rotacionado de bovinos por cerca de dois anos. O período de entrada de animais na área foi compreendido entre agosto de 2012 a abril de 2014, sendo adotada uma média de 50 vacas adultas ou bezerros por entrada em toda área experimental. Após esse período, a pastagem foi mantida em repouso por cerca de um ano. 
O delineamento experimental foi em blocos casualizados (DBC), com 12 repetições, sendo desenvolvido em esquema fatorial $2 \times 4$, com avaliação dos fatores: uso de irrigação e forma de suprimento de nitrogênio. Os tratamentos foram: $400 \mathrm{~kg} / \mathrm{ha}$ de $\mathrm{N}$, na forma de ureia (T1); $400 \mathrm{~kg} / \mathrm{ha}$ de $\mathrm{N}$, na forma orgânica via esterco bovino (T2); $400 \mathrm{~kg} / \mathrm{ha}$ de $\mathrm{N}, 50 \%$ na forma mineral e $50 \%$ na forma orgânica, utilizando-se as mesmas fontes (T3) e a testemunha, sem adubação nitrogenada (T4). As adubações foram parceladas em quatro aplicações, com 30, 25,20 e $10 \%$ da dose total, sendo realizadas a lanço. Os tratamentos foram conduzidos em dois ambientes, sendo um irrigado por aspersão em malha fixa e outro em sequeiro. A aplicação das lâminas de irrigação ocorreu em conformidade com a demanda evapotranspirométrica, calculada a partir do monitoramento das condições meteorológicas. A primeira e a última irrigação foram realizadas em janeiro de 2012 e setembro de 2013, respectivamente. A duração média da irrigação em cada seção foi de uma hora.

Em setembro de 2015, dois anos após a última irrigação, foi executada a avaliação da resistência do solo à penetração de raízes (RP), em solo com baixo teor de umidade, por meio da utilização de um penetrômetro de impacto modelo IAA/PLANALSUCAR-STOLF com ponto fina (30) (STOLF, 2014). O funcionamento do equipamento consiste, basicamente, na penetração de uma haste fina no solo. Essa haste é constituída por um material metálico e contém uma ponteira cônica presa à sua extremidade. A penetração ocorre por meio do impacto ocasionado pelo acionamento manual de um êmbolo de massa conhecida (4 kg), a uma altura constante $(40 \mathrm{~cm})$. Avaliou-se o número de impactos necessários para a penetração da haste até a camada de $50 \mathrm{~cm}$. Posteriormente, o número de impactos foi convertido para a unidade de $\mathrm{Kgf}_{\mathrm{cm}}^{-2}$, a partir do uso da Equação 1 proposta por STOLF (1991):

$$
\mathrm{RP}=5,6+6,98 \mathrm{~N}
$$

em que:

$\mathrm{RP}=$ Resistência do solo à Penetração, $\mathrm{Kgf} \mathrm{cm}^{-2}$

$\mathrm{N}$ = número de impactos por decímetro.

Os resultados obtidos para a resistência mecânica do solo foram classificados em conformidade com a Tabela 1.

TABELA 1 - Classes de resistência do solo à penetração (RP). Adaptadas de SOILSURVEY STAFF (1993).

\begin{tabular}{ll}
\hline Classe & $\mathrm{RP}(\mathrm{MPa})$ \\
\hline Extremamente baixa & $<0,01$ \\
Muito baixa & $0,01-0,1$ \\
Baixa & $0,1-1,0$ \\
Moderada & $1,0-2,0$ \\
Alta & $2,0-4,0$ \\
Muito alta & $4,0-8,0$ \\
Extremamente alta & $>8,0$ \\
\hline
\end{tabular}

Para a determinação da umidade, foram coletadas amostras de solo com o auxilio de um trado holandês, nas camadas 0-20, 20-40 e 40-50 cm, em três pontos 
por parcela. Em laboratório, as amostras foram pesadas e, em seguida, secas em estufa a $105^{\circ}$ por 24 horas. Os dados foram submetidos à análise de variância (ANAVA), aplicando-se o teste $F(p<0,05)$ e, quando significativo, foi utilizado o teste de Scott-Knott a $5 \%$ de significância. As análises estatísticas foram realizadas com 0 auxilio da linguagem $R$, pacote ExpDes (FERREIRA et al., 2014).

Realizou-se a análise granulométrica e a determinação do teor de carbono orgânico $(C)$ na camada $0-10 \mathrm{~cm}$, para fins de caracterização do solo. Por meio da multiplicação de $\mathrm{C}$ pelo fator de Van Bemmelen, foi calculada a porcentagem de matéria orgânica do solo (MOS), conforme a Equação 2.

$\operatorname{MOS}=1,724 \mathrm{C}$

em que:

MOS = matéria orgânica do solo, $\mathrm{g} \mathrm{Kg}^{-1}$;

$\mathrm{C}=$ carbono orgânico, $\mathrm{g} \mathrm{Kg}^{-1}$;

1,724 = fator de Van Bemmelen.

Foram feitas análises de correlação linear entre MOS e RP nas camadas 0-5 e 5-10 cm, empregando-se o software SigmaPlot $\AA^{\circledR}$.

Os resultados da análise granulométrica e da porcentagem de MOS são expostos na Tabela 2.

TABELA 2 - Teores das frações areia, silte, argila e porcentagem de matéria orgânica no solo (MOS) de um Latossolo Vermelho distrófico na camada 0-10 cm.

\begin{tabular}{|c|c|c|c|c|}
\hline Tratamentroc & Areia & Silte & Argila & MOS \\
\hline T1 & 21,53 & 18,02 & 60,46 & 4,60 \\
\hline T2 & 22,95 & 17,44 & 59,62 & 4,86 \\
\hline T3 & 23,45 & 16,07 & 60,49 & 4,73 \\
\hline T4 & 22,06 & 18,01 & 59,94 & 4,22 \\
\hline
\end{tabular}

Análise granulométrica: método da pipeta e solução dispersante de $\mathrm{NaOH} \mathrm{1,0} \mathrm{M.}$

Porcentagem de MOS: método Walkley-Black (WALKLEY \& BLACK, 1934).

\section{RESULTADOS E DISCUSSÃO}

A Tabela 3 apresenta o resumo da análise de variância para a resistência mecânica do solo por camada analisada. Observa-se que não houve diferença significativa entre as formas de suprimento de nitrogênio, para todos os intervalos de profundidade $(p<0,05)$. Em contrapartida, verificou-se diferença significativa $(p<0,05)$ para o fator regime hídrico nas camadas 5-10, 10-15 e 15-20 cm. 
TABELA 3 - Resumo da análise de variância para resistência do solo à penetração por camada avaliada de um Latossolo Vermelho distrófico sob pastagem de capim-tifton 85.

\begin{tabular}{ccccc}
\hline FV & Bloco & Regime hídrico & Forma de N & Regime x Forma \\
\cline { 2 - 5 } GL & 1 & 1 & 3 & 3 \\
\hline Camadas (cm) & \multicolumn{4}{c}{ QM } \\
\cline { 2 - 5 } $0-5$ & $0,22^{\text {ns }}$ & $2,33^{\text {ns }}$ & $3,74^{\text {ns }}$ & $1,82^{\text {ns }}$ \\
$5-10$ & $5,78^{\text {ns }}$ & $57,58^{*}$ & $1,00^{\text {ns }}$ & $5,61^{\text {ns }}$ \\
$10-15$ & $50,56^{*}$ & $28,50^{*}$ & $3,18^{\text {ns }}$ & $8,46^{\text {ns }}$ \\
$15-20$ & $37,74^{*}$ & $29,89^{*}$ & $1,95^{\text {ns }}$ & $14,48^{\text {ns }}$ \\
$20-25$ & $13,28^{\text {ns }}$ & $14,37^{\text {ns }}$ & $2,28^{\text {ns }}$ & $15,80^{\text {ns }}$ \\
$25-30$ & $2,63^{\text {ns }}$ & $2,67^{\text {ns }}$ & $8,89^{\text {ns }}$ & $5,64^{\text {ns }}$ \\
$30-35$ & $5,85^{\text {ns }}$ & $2,03^{\text {ns }}$ & $3,00^{\text {ns }}$ & $5,53^{\text {ns }}$ \\
$35-40$ & $2,02^{\text {ns }}$ & $0,05^{\text {ns }}$ & $2,09^{\text {ns }}$ & $3,45^{\text {ns }}$ \\
$40-45$ & $2,86^{\text {ns }}$ & $2,02^{\text {ns }}$ & $3,41^{\text {ns }}$ & $6,65^{\text {ns }}$ \\
$45-50$ & $0,01^{\text {ns }}$ & $1,82^{\text {ns }}$ & $1,97^{\text {ns }}$ & $6,75^{\text {ns }}$ \\
\hline
\end{tabular}

ns: Não significativo; *Significativo a $5 \%$ de probabilidade.

Na Figura 1, são expressos os resultados da resistência do solo à penetração (RP) para o ambiente irrigado (Figura 1a) e de sequeiro (Figura 1b), até $50 \mathrm{~cm}$ de profundidade. Constatou-se que os maiores valores médios de RP ocorreram na camada $5-10 \mathrm{~cm}$ para o regime irrigado $(10,51 \mathrm{MPa})$ e na camada $10-15 \mathrm{~cm}$ para o regime de sequeiro $(9,04 \mathrm{MPa})$. De acordo com a Tabela 1 , esses valores são classificados na classe de resistência mecânica extremamente alta.

Para ambos os regimes hídricos, os menores valores médios ocorreram na última camada avaliada $(45-50 \mathrm{~cm})$, sendo iguais a 3,96 MPa e 4,06 MPa para o ambiente com e sem irrigação, respectivamente. Conforme a Tabela 1, esses valores pertencem, nessa ordem, às classes de resistência alta e muito alta.

Em seu estudo sobre os atributos físicos de um Latossolo Vermelho eutrófico típico cultivado com capim-tifton 85, BASSO et al. (2014) observaram as maiores médias de RP nas camadas do solo entre 5 a $20 \mathrm{~cm}$ de profundidade, o que corrobora com os resultados obtidos neste trabalho. Segundo os autores, a maior concentração de raízes ocorre nos primeiros $15 \mathrm{~cm}$ de profundidade, o que é associado ao aumento da RP. Os valores verificados pelos autores nessas camadas também se encontraram acima de $2,50 \mathrm{MPa}$, o qual corresponde ao valor crítico para o bom desenvolvimento das pastagens perenes (IMHOFF et al., 2000).

Embora não haja um consenso sobre os valores de resistência mecânica que são limitantes ao desenvolvimento das plantas, normalmente o intervalo de 2,00 a 2,50 MPa é sugerido como impeditivo ao desenvolvimento radicular em pastagens (BASSO et al, 2014; OLIVEIRA et al., 2015). Dessa forma, constata-se que o solo em estudo apresentou condições de resistência mecânica muito restritivas ao desenvolvimento adequado do capim-tifton 85 , em ambos os regimes hídricos. 


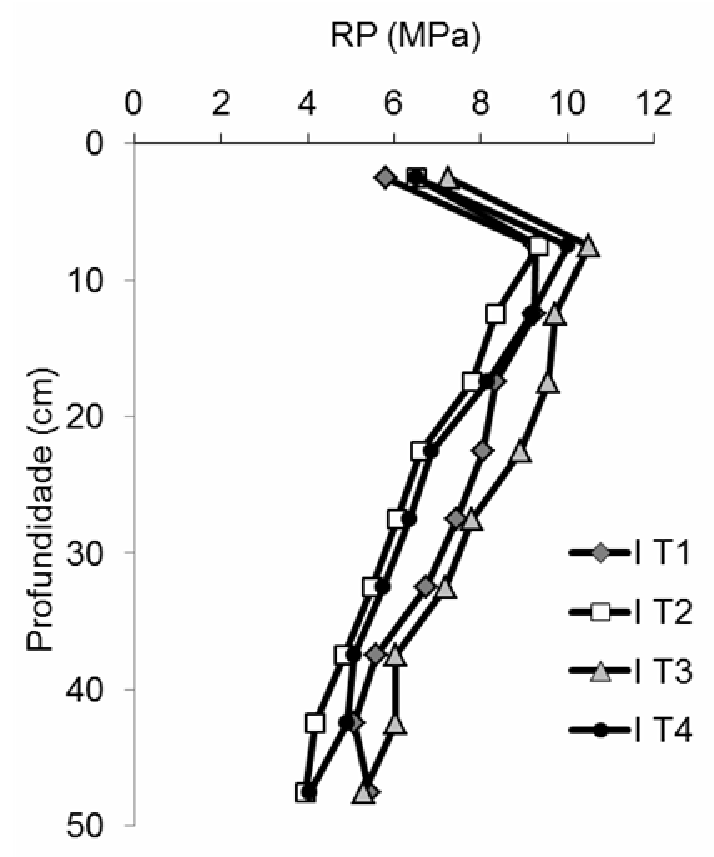

(a)

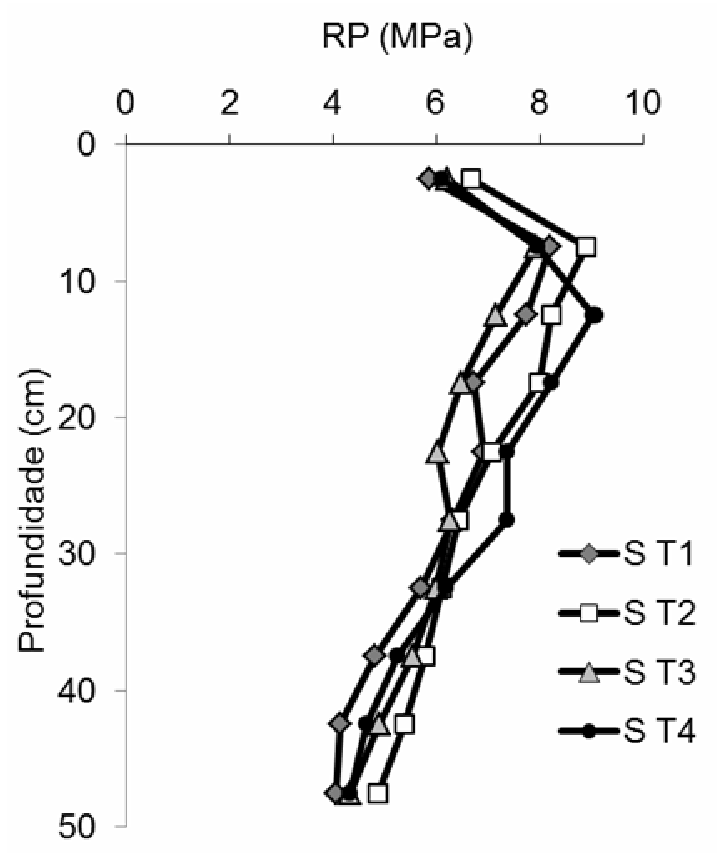

(b)

FIGURA 1. Resistência à penetração $(\mathrm{RP})$ até $50 \mathrm{~cm}$ de profundidade para os tratamentos aplicados em um Latossolo Vermelho distrófico sob capimtifton 85, em área com (a) e sem irrigação (b). $400 \mathrm{~kg} / \mathrm{ha}$ de ureia (T1); $400 \mathrm{~kg} / \mathrm{ha}$ de esterco bovino (T2); $400 \mathrm{~kg} / \mathrm{ha}$ de ureia e de esterco bovino, na proporção 1:1 (T3) e sem adubação nitrogenada (T4).

Salienta-se que os resultados de resistência à penetração (RP) podem ser condicionados pelo teor atual de água no solo, conforme amplamente divulgado na literatura (IMHOFF et al., 2000; SILVEIRA et al., 2010; COSTA et al., 2012; TORRES et al., 2012; TAVARES et al., 2014). Essa importante associação normalmente é caracterizada por uma correlação negativa, na medida em que para uma redução da umidade, ocorre aumento da RP, devido à influência da água sobre a coesão entre as partículas do solo (SILVEIRA et al, 2010; BASSO et al, 2014).

Além disso, segundo o fabricante do equipamento utilizado, a umidade ideal para a medição da RP é na capacidade campo do solo, uma vez que essa condição permite boa relação com o crescimento radicular das plantas. Diante do exposto, pode-se inferir que os elevados valores de RP obtidos estão relacionados ao baixo teor de água presente no solo durante a execução dos testes de penetrometria, tanto na área irrigada até dois anos antes da avaliação (Figura 2a), quanto nos piquetes sem irrigação (Figura 2b). Ademais, vale ressaltar a contribuição do clima regional para a perda de umidade do solo, uma vez que não houve registro de precipitação durante o período de 50 dias antecedentes à realização das avaliações. 


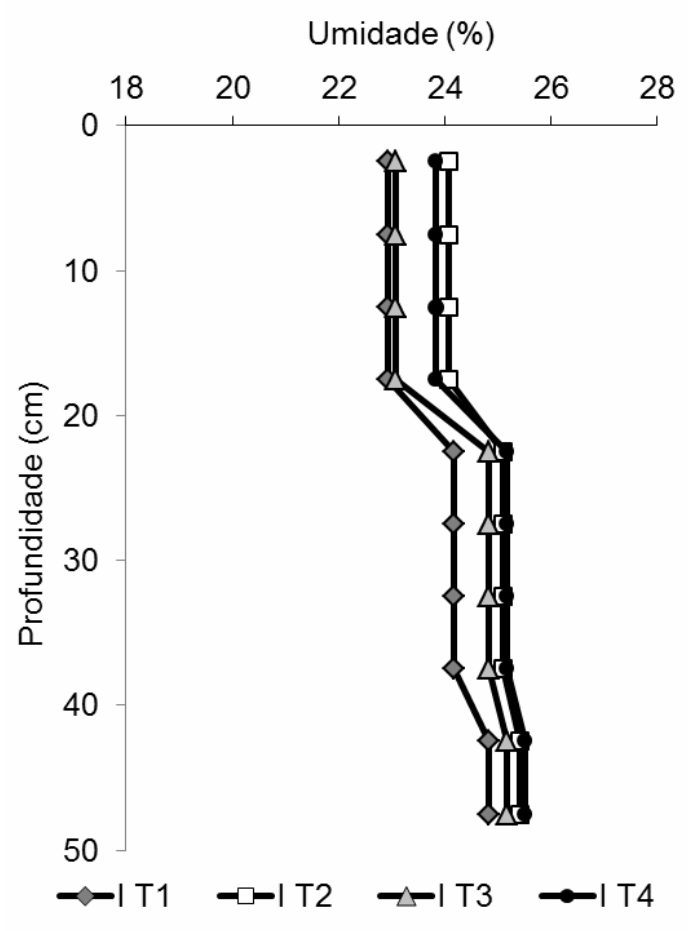

(a)

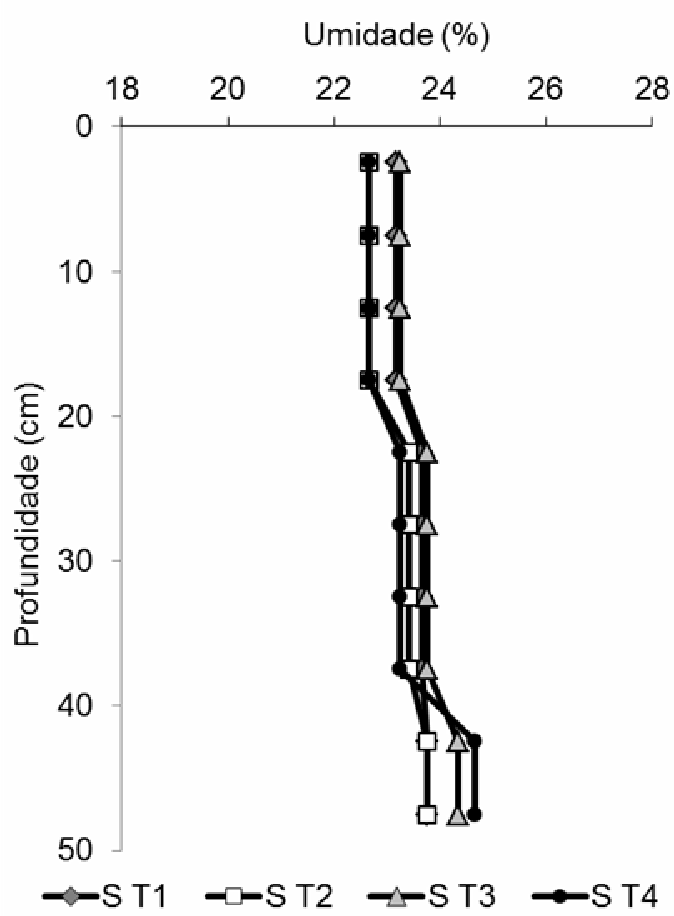

(b)

FIGURA 2. Umidade do solo medida nas camadas $0-20,20-40$ e $40-50 \mathrm{~cm}$, para os tratamentos aplicados em um Latossolo Vermelho distrófico sob capimtifton 85, em área com (a) e sem irrigação (b). $400 \mathrm{~kg} / \mathrm{ha}$ de ureia (T1); $400 \mathrm{~kg} / \mathrm{ha}$ de esterco bovino (T2); $400 \mathrm{~kg} / \mathrm{ha}$ de ureia e de esterco bovino, na proporção 1:1 (T3) e sem adubação nitrogenada (T4).

Além da umidade do solo, outros fatores influenciam na determinação da RP por penetrômetros dinâmicos, tais como a textura do solo, a mineralogia da fração argila, a presença de pedras, a densidade e a estrutura do solo, a porcentagem de matéria orgânica no solo (MOS) e os diferentes manejos empregados (SILVEIRA et al., 2010; TAVARES et al., 2014). Uma vez que os tratamentos foram avaliados em uma mesma classe de solo, dentre os fatores anteriormente relacionados, a matéria orgânica pode sofrer alteração pelo manejo e influir na RP. Contudo, neste trabalho, não foram verificadas correlações significativas $(p<0,05)$ entre MOS e as formas de adubação nitrogenada, em ambos os regimes hídricos (Tabela 4). Esse resultado pode ser atribuído ao tempo de aplicação dos tratamentos (dois anos), o qual foi insuficiente para induzir alterações na resistência do solo à penetração de raízes.

Observações semelhantes foram realizadas por MOURA et al. (2012), estudando o efeito da aplicação de dejetos líquidos suínos (DLS) e de cama de frango na resistência à penetração de um Latossolo Vermelho distroférrico em pastagem de Brachiaria decumbens, durante dois anos de avaliação. Os autores constataram que a aplicação de ambos os compostos não influenciou a RP, sendo que os valores dos tratamentos se mantiveram semelhantes à testemunha, sem nenhuma aplicação. Na mesma linha, AGNE \& KLEIN (2014) também verificaram que o emprego de diferentes doses de DSL, por um período de quatro anos em um Latossolo Vermelho sob pastagem perene, não induziu modificações nos atributos físicos do solo investigados, incluindo a resistência à penetração. 
TABELA 4 - Coeficientes de correlação linear ( $r$ ) e níveis de significância ( $p$-valor) entre resistência à penetração $(R P)$ e teor de matéria orgânica (MOS) em um Latossolo Vermelho distrófico nas camadas $0-5$ e $5-10 \mathrm{~cm}$, para dois regimes hídricos.

\begin{tabular}{ccccc}
\hline & \multicolumn{2}{c}{ Regime irrigado } & \multicolumn{2}{c}{ Regime de sequeiro } \\
\hline & $0-5 \mathrm{~cm}$ & $5-10 \mathrm{~cm}$ & $0-5 \mathrm{~cm}$ & $5-10 \mathrm{~cm}$ \\
\cline { 2 - 5 } $\mathrm{r}$ & $-0,067$ & $-0,434$ & 0,800 & 0,788 \\
$\mathrm{p}$-valor & 0,933 & 0,566 & 0,200 & 0,212 \\
\hline
\end{tabular}

O efeito do regime hídrico na resistência à penetração foi significativo para as camadas 5-10, 10-15 e 15-20 cm (Tabela 3), sendo que o ambiente irrigado apresentou médias de resistência à penetração (RP) superiores (Figura 3). WENDLING et al. (2012) ressaltam que o aumento da RP em áreas de pastagem pode estar relacionado ao excesso de carga animal pelo emprego de diferentes lotações, alterando as propriedades do solo devido à compactação causada pelo pisoteio animal.

Considerando que todos os piquetes foram submetidos à mesma lotação sob manejo intensivo, o resultado alcançado pode ser atribuído à maior suscetibilidade dos solos irrigados à compactação, em virtude do maior teor de água contido nesses solos (LIMA et al., 2012). Esse fator, aliado à excessiva carga animal, acarretou em altos valores de RP, mesmo com o cultivo de uma espécie com potencial para a descompactação biológica do solo.

Neste estudo, a RP no ambiente irrigado foi superior, mesmo sob um teor de água semelhante no momento da análise $(5-20 \mathrm{~cm})$, ou foi estatisticamente igual à RP do ambiente de sequeiro em camadas com umidade maior, exceto na camada 0$5 \mathrm{~cm}$ (Figuras 3 e 4). Essas observações apontam que, entre o período de dois anos decorrido entre a última irrigação e a realização dos testes, o efeito negativo da irrigação na RP foi persistente na camada subsuperficial e, portanto, sugere-se que o capim-tifton 85 foi capaz de promover a descompactação do solo apenas na camada superficial $(0-5 \mathrm{~cm})$, durante o intervalo de tempo considerado. LIMA et al. (2012) verificaram que o capim-coastcross (Cynodon spp.) sob solo corrigido e condicionado quimicamente, sem entrada de animais e máquinas, foi capaz de melhorar a estrutura do solo em seis meses, mesmo após intensa compactação. 


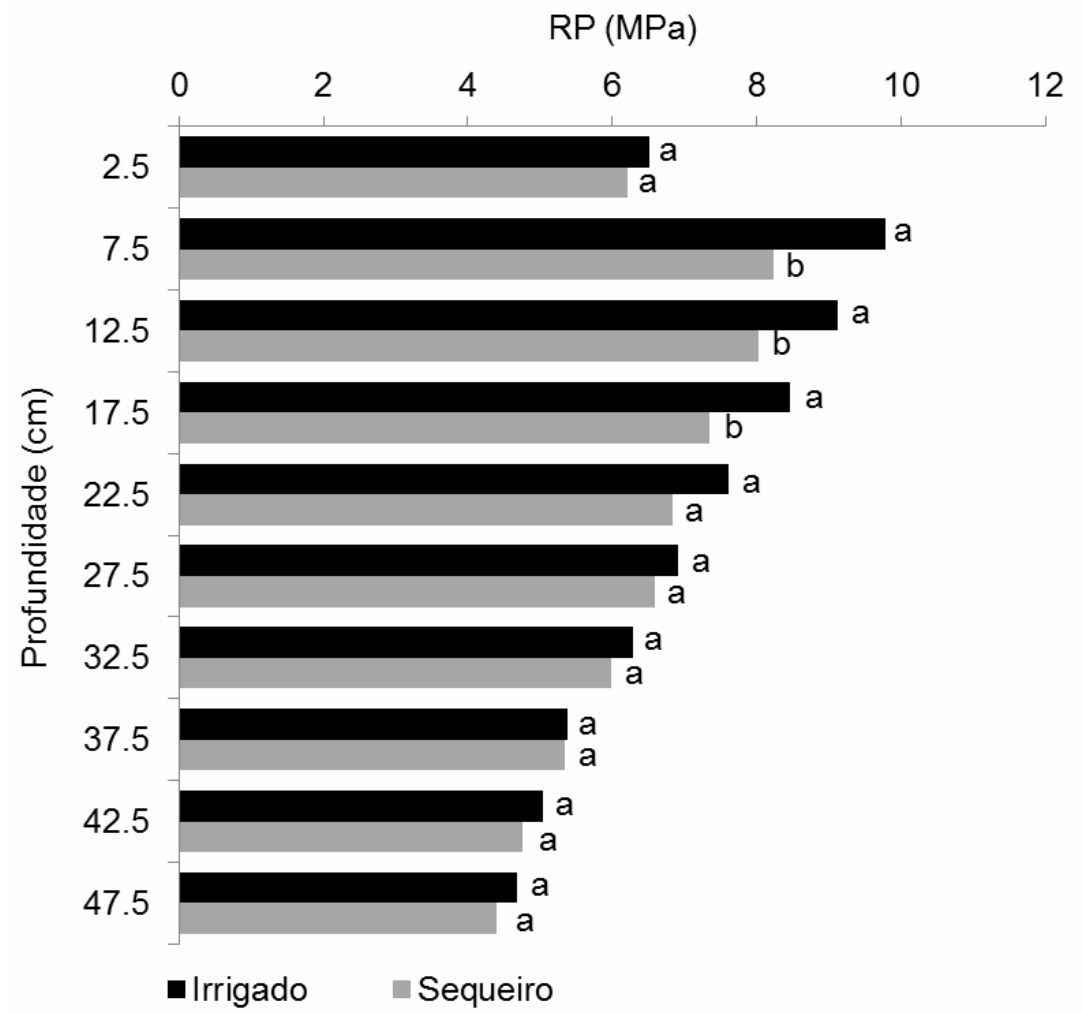

FIGURA 3. Resistência à penetração (RP) até $50 \mathrm{~cm}$ de profundidade para dois regimes hídricos em um Latossolo Vermelho distrófico sob capimtifton 85. Médias com letras iguais comparando os ambientes para cada atributo não diferem entre si, pelo teste de Scott-Knott.

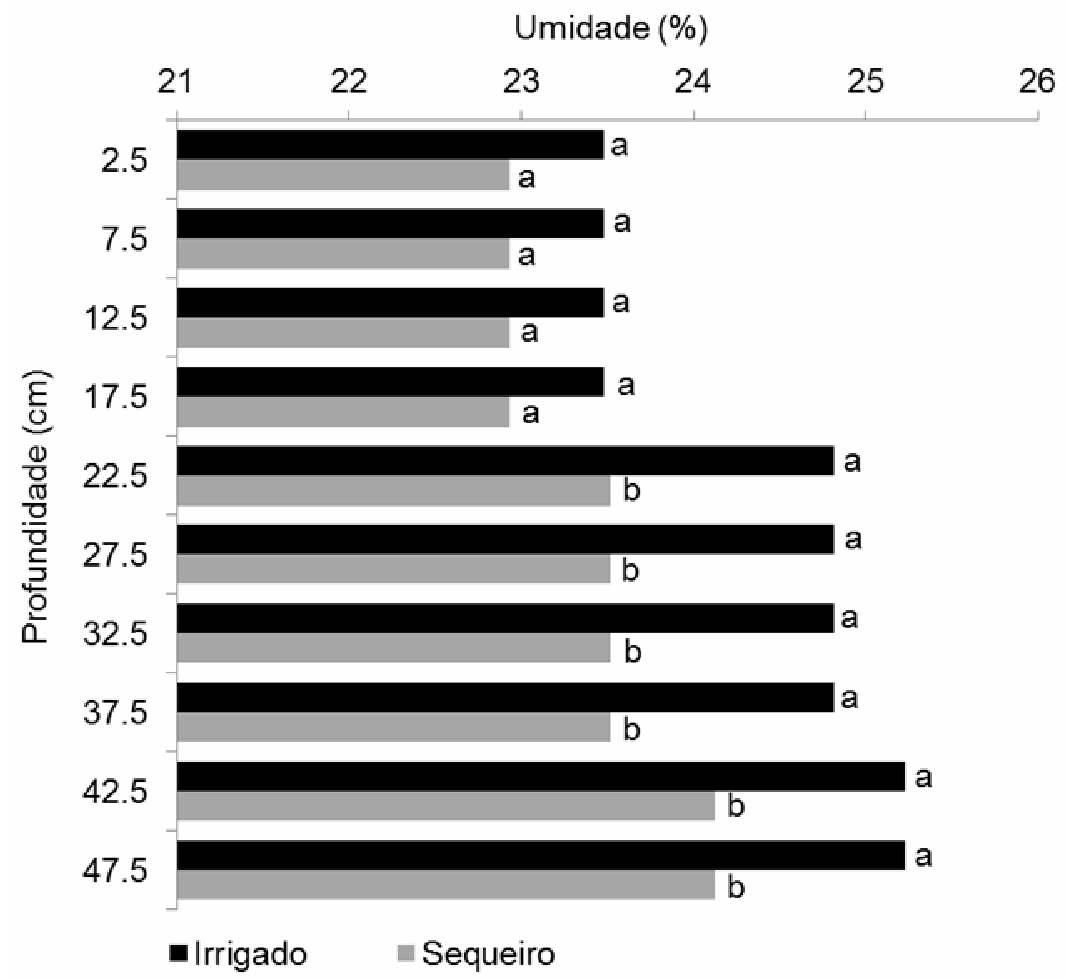

FIGURA 4. Umidade do solo medida nas camadas 0-20, 20-40 e 40-50 cm para dois regimes hídricos em um Latossolo Vermelho distrófico sob capim-tifton 85. Médias com letras iguais comparando os ambientes para cada atributo não diferem entre si, pelo teste de Scott-Knott. 


\section{CONCLUSÃO}

A fonte de nitrogênio para adubação de capim-tifton 85 indica ser pouco relevante para alterações significativas na resistência à penetração de um Latossolo Vermelho distrófico argiloso, durante dois anos de aplicação. Entretanto, a irrigação sob pastejo intensivo favorece a compactação do solo, mesmo com a capacidade de descompactação biológica do solo atribuída à espécie empregada. Portanto, a irrigação de pastagens deve ser utilizada com parcimônia, evitando-se a sua aplicação em áreas com elevada lotação animal.

\section{AGRADECIMENTOS}

À UFSJ, À EPAMIG ao CNPq pelos recursos disponibilizados para a realização deste trabalho.

\section{REFERÊNCIAS}

AGNE, S. A. A; KLEIN, V. A. Matéria orgânica e atributos físicos de um Latossolo Vermelho após aplicações de dejeto de suínos. Revista Brasileira de Engenharia Agrícola e Ambiental, v. 18, n. 7, p. 720-726, 2014. Disponível em: <http://dx.doi.org/10.1590/S1415-43662014000700008>. doi: 10.1590/S1415-4366 2014000700008

BASSO, C. J.; PIAS, O. H. C.; SANTI, A. L.; BIER, D. R.; PINTO, M. A. B. Variabilidade da produção do Tifton 85 e sua correlação com os atributos físicos do solo. Brazilian Journal of Agricultural Sciences/Revista Brasileira de Ciências Agrárias, v. 9, n. 4, 2014. Disponível em: <http://www.agraria.pro.br/sistema/ index.php?journal=agraria\&page $=$ article $\& o p=v i e w \& p a t h \% 5 B \% 5 \mathrm{D}=$ agraria_v9i4a439 5\&path\%5B\%5D=1686>. doi: 10.5039/agraria.v9i4a4395

CARASSAI, I. J.; CARVALHO, P. C. F.; CARDOSO, R. R.; FLORES, J. P. C.; ANGHINONI, I.; NANBINGER, C.; FREITAS, F. K.; MACARI, S. Atributos físicos sob intensidades de pastejo e métodos de pastoreio com cordeiros em integração lavoura-pecuária. Pesquisa Agropecuária Brasileira, Brasília, DF, v.46, p.12841290, 2011. Disponível em: <http://dx.doi.org/10.1590/S0100-204X2011001000024>. doi: 10.1590/S0100-204X2011001000024

COLUSSI, G; SILVA, L. S.; MINATO, E. A.. Escarificação e adubação orgânica: efeito na recuperação estrutural de solo produzindo Tifton 85. Ciência Rural, Santa Maria, v.44, n.11, p.1956-1961, nov, 2014. Disponível em: <http://dx.doi. org/10.1590/0103-8478cr20131670 > doi: 10.1590/0103-8478cr20131670

COSTA, M. A. T.; TORMENA, C. A.; LUGÃO, S. M. B.; FIDALSKI, J.; NASCIMENTO, W. G.; MEDEIROS, F. M. Resistência do solo à penetração e produção de raízes e de forragem em diferentes níveis de intensificação do pastejo. Revista Brasileira de Ciência do Solo, v. 36, p. 993-1004, 2012. Disponível em: <http://dx.doi.org/10.1590/S0100-06832012000300029>. doi: 10.1590/S0100-0683 2012000300029

EMBRAPA. Sistema Brasileiro de Classificação de Solos. 3 ed. Brasília, DF: Embrapa Solos, 353 p. 2013

FERREIRA, E. B.; CAVALCANTI, P. P.; NOGUEIRA, D. A. ExpDes: an R package for ANOVA and experimental designs. Applied Mathematics, Alfenas, v. 5, n. 19, p. 
2952, 2014. Disponível em: <http://www.scirp.org/journal/Paperlnformation.aspx? Pape ID=51204 >. doi: 10.4236/am.2014.519280

FIDALSKI, J.; TORMENA, C. A.; CECATO, U.; BARBERO, L. M.; LUGÃO, S. M. B.; COSTA, M. A. T. Qualidade física do solo em área de pastagem adubada e sob pastejo contínuo. Pesquisa agropecuária brasileira, Brasília, v.43, n.11, p.15831590, nov. 2008. Disponível em: <http://dx.doi.org/10.1590/S0100204X2008001100018>. doi: 10.1590/S0100-204X2008001100018

IBGE. Minas Gerais, Prudente de Morais, infográficos: histórico. IBGE Cidades, 2013. Disponível em: <http://ibge.gov.br/cidadesat/painel/historico.php?lang=\& codmun=315360\&search=minasgeras $\mid$ prudente-de-morais $\mid$ infograficos:-historico $>$.

IMHOFF, S.; SILVA, A. P.; TORMENA, C. A. Aplicações da curva de resistência no controle da qualidade física de um solo sob pastagem. Pesquisa Agropecuária Brasileira, v. 35, n. 7, p. 1493-1500, 2000. <http://dx.doi.org/10.1590/S0100 204X2000000700025>. doi: 10.1590/S0100 204X2000000700025

LIMA, V. M. P.; OLIVEIRA, G. C.; SERAFIM, M. E.; CURI, N.; EVANGELISTA, A. R. Intervalo hídrico ótimo como indicador de melhoria da qualidade estrutural de Latossolo degradado. Revista Brasileira de Ciência do Solo, v. 36, p.71-78, 2012. Disponível em: <http://dx.doi.org/10.1590/S0100-06832012000100008>. doi: 10.1590/S0100-06832012000100008

LLANILLO, R. F., RICHART, A., TAVARES FILHO, J., DE FÁTIMA GUIMARÃES, M., \& FERREIRA, R. R. Evolução de propriedades físicas do solo em função dos sistemas de manejo em culturas anuais. Semina: Ciências Agrárias, Londrina, v. 27, n. 2, p. 205-220, 2006. Disponível em: <http://dx.doi.org/10.5433/16790359.2006v27n2p205>. doi: 10.5433/1679-0359

MOURA, J. B.; MARASCA, I.; MENESES, L. A. S.; PIRES, W. M.; MEDEIROS, L. C. Resistência à penetração do solo em pastagem cultivada com Brachiaria decumbens sob aplicação de dejetos líquidos suínos e cama de frango. Global Science and Technology, v. 5, n. 3, 2012. Disponível em: <http://rv.ifgoiano.edu.br/periodicos/ index.php/gst/article/view/455/329>.

NEIVA JÚNIOR, E., ROCHA, W. W.; PIRES, B. S.; FARNEZI, M. M. M.; DIAS JUNIOR, M. S.; FREITAS, D. F. B.; SILVA, E. B.; CARVALHO, G. A. O. Compressiblity and penetrability of latossolo vermelho-amarelo distrófico (oxisol) under varied management systems and land uses. Revista Brasileira de Ciência do Solo, v. 39, p. 86-93, 2015. Disponível em: <http://dx.doi.org/10.1590/ 01000683rbcs20150032>. doi: 10.1590/01000683rbcs20150032

OLIVEIRA, A. P. P.; LIMA, E.; ANJOS, L. H. C.; ZONTA, E.; PEREIRA, M. G. Sistemas de colheita da cana-de-açúcar: Conhecimento atual sobre modificações em atributos de solos de tabuleiro. Revista Brasileira de Engenharia Agrícola e Ambiental. Campina Grande-PB, v. 18, n. 9, p. 939-947, 2014. Disponível em: <http://dx.doi.org/10.1590/1807-1929/agriambi.v18n09p939-947>. doi: 10.1590/1807 -1929/agriambi.v18n09p939-947

OLIVEIRA, D. M. S; LIMA, R. P.; VERBURG, E. E. J. Qualidade física do solo sob diferentes sistemas de manejo e aplicação de dejeto líquido suíno. Revista 
Brasileira de Engenharia Agrícola e Ambiental, v. 19, n. 3, p. 280-285, 2015. Disponível em: <http://dx.doi.org/10.1590/1807-1929/agriambi.v19n3p280-285>. doi: 10.1590/1807-1929/agriambi.v19n3p280-285

PERON, A. J.; EVANGELISTA, A. R. Degradação de pastagens em regiões de cerrado. Ciência e Agrotecnologia, Lavras, v. 28, n. 3, p. 655-661, 2004. Disponível em: <http://dx.doi.org/10.1590/S1413-70542004000300023>. doi: 10.1590/S141370542004000300023

SILVA, É. A.; OLIVEIRA, G. C.; CARDUCCI, C. E.; SILVA, B. M.; OLIVEIRA, L. M.; COSTA, J. C. Increasing doses of agricultural gypsum, aggregate stability and organic carbono in Cerrado Latosol under Coffee crop. Revista de Ciências Agrárias/Amazonian Journal of Agricultural and Environmental Sciences, v. 56, n. 1, p. 25-32, 2013. Disponível em: <http://doi.editoracubo.com.br/ 10.4322/rca. 2013.012>. doi: 10.4322/rca.2013.012

SILVEIRA, D. C.; MELO FILHO, J. F.; SACRAMENTO, J A. A. S.; SILVEIRA, E. C. $P$. Relação umidade versus resistência à penetração para um Argissolo Amarelo distrocoeso no recôncavo da Bahia. Revista Brasileira de Ciência do Solo, v. 34, n. 3, p. 659-667, 2010. Disponível em: <http://dx.doi.org/10.1590/S010006832010000300007>. doi: 10.1590/S0100-06832010000300007

SOIL SURVEY STAFF. Soil survey manual. Washington, USDASCS. U.S. Gov. Print. Office, 1993. 437p. (Handbook, 18).

STOLF, R. Penetrômetro de impacto Stolf - Programa computacional de dados em Excel-VBA. Revista Brasileira de Ciência do Solo, Araras, v. 38, p. 774-782, 2014. Disponível em: <http://dx.doi.org/10.1590/S0100-06832014000300009>. doi: 10.1590/S0100-06832014000300009

STOLF, R. Teoria e teste experimental de fórmulas de transformação dos dados de penetrômetro de impacto em resistência do solo. Revista Brasileira de Ciência do Solo, Campinas, v. 15, n. 2, p. 229-35, 1991. Disponível em: <https://www.cca. ufscar.br/drnpa/hprubismar_ARTIGOS/63._Teoria_e_teste_de_transformacao_dos_ dados_de_penetrometro_de_impacto_em_resistencia_do_solo_(Stolf,R.).pdf>.

TAVARES, U. E.; MONTENEGRO, A. A. A.; ROLIM, M. M.; SILVA, J. S.; SILVA, T. F. V.; ANDRADE, C. W. L. Variabilidade espacial da resistência à penetração e da umidade do solo em Neossolo Flúvico. Water Resources and Irrigation Management, v. 3, n. 2, p. 79-89, 2014. Disponível em: <http://dx.doi.org/10.19149/ 2316-6886/wrim.v3n2p79-89>. doi: 10.19149/2316-6886/wrim.v3n2p79-89

TORRES, J. L. R.; RODRIGUES-JUNIOR, D. J.; SENE. G. A.; JAIME, D. G.; VIEIRA, D. M. S. Resistência à penetração em área de pastagem de capim tifton influenciada pelo pisoteio e irrigação. Bioscience Journal, v.28, n.1 p.232-239, 2012. Disponível em: <http://www.seer.ufu.br/index.php/bioscience journal/article/view/12546/8368>.

WALKLEY, A.; BLACK, I. A. An examination of the Degtjareff method for determining soil organic matter and a proposed modification of the chromic acid titration method. Soil Science, Baltimore, v. 37, n. 1, p. 29-38, jan./jun.1934. Disponível em: $<$ http://journals.Iww.com/soilsci/Citation/1934/01000/AN_EXAMINATION_OF_THE_ DEGTJAREFF_METHOD_FOR.3.aspx>. 
WENDLING, B.; VINHAL-FREITAS, I. C.; OLIVEIRA, R. C.; BABATA, M. M.; BORGES, E. N. Densidade, agregação e porosidade do solo em áreas de conversão do cerrado em floresta de pinus, pastagem e plantio direto. Bioscience Journal, v. 28, p. 256-265, 2012. Disponível em: < http://www.seer.ufu.br/index.php/bioscience journal/article/view/13277/8371>. 